\title{
Reflections on the death of Diana, Princess of Wales
}

\author{
Elinor Kapp
}

Apparently more than 15 books have already been written about the death of Diana and the associated phenomena, and as many again are shortly to be published. You will be glad to know that I am not writing one of them. Nor am I going to add to the numerous research papers, since I cannot write phrases like "Diana functions as a radical fetish of virtual reality, a move beyond alienation to a principle of otherness raised to perfection" (Diane Rubinstein in That's the Way the Mercedes Benz: Di, Wound Culture and Fatal Fetishism: The Sunday Times, 5 April 1998). The humorist, Alan Coren writes that soon we will all have to undergo official tests on our attitude to Di before we will be allowed a mortgage, a credit card, or a subscription to Reader's Digest, the catch being we will never know if we should be for or against her.

We can assume that some individuals will have responded to her death at either extreme of a spectrum ranging from indifference to a reaction of identification and severe distress. The majority of us will have been somewhere along the spectrum, not fixed but moving within a span. Many people have described being surprised by the depth of their own responses and also by the mixed and contradictory nature of their feelings. At least as psychiatrists we know that it is part of the human condition to hold opposite feelings at the same time and that atavistic and magical ideas often surge up unexpectedly in the most rational of souls. We also know that, as communal creatures, we seek out subgroups of our culture to clarify and stabilise our own feelings and to make sense of events. A large subgroup were those who travelled distances to lay flowers in front of Buckingham Palace and wept openly in the streets. Irritation at media hype - even several million people are not 'all the nation' should not lead us to minimise the events nor to belittle the sincere feelings that were expressed. It is similarly important to recognise a substantial subgroup who rejected and resented the emotional outpouring, taking refuge in describing it as a manipulation by guilt ridden journalists.
There are some points that are obvious enough not to need labouring. We know from our clinics that many people have never grieved sufficiently for losses and traumas in their lives. In our deritualised and secularised society a great event like this with a sudden catastrophe, week of mourning and a public funeral can allow such people a catharsis and healing of their own pockets of unresolved grief. Much of the anger directed towards the media, the royal family and the car driver must have allowed a similar safe displacement of private anger and guilt.

It would be only fair to say that my own reactions were as mixed as anyone's. The previous airing of the couples unhappy marriage had aroused a not uncommon mixture of schadenfreude, sympathy and distaste in me. Diana herself, known only through her dance with the media, had seemed neurotic, manipulative and charismatic, a blend arousing professional as much as personal uneasiness. On a much smaller scale I am sure we have all known in clinical practice a few of these 'iconic' people. who seem to flare through life like meteors often coming to tragic ends, but sometimes working through their neurotic problems and becoming ordinary and settled. Much that was written afterwards about Diana softened my view of her. She seemed to have tried to reach out to people with kind acts even outside media exposure and to use her image positively, at least in more recent times.

Friends living in London described how, in the days following Diana's death many open places other than those around the palace became sites for ritual placing of flowers, candles and photos. not exclusively of Diana. These were outside the area of media interest and on enquiry I learned that many occurred in other cities, in parks or church grounds or other memorial areas, akin to the flowers that in recent years are left at the sites of road accidents or murders. These little shrines, manifest signs of grief and love, are an expression of a deep and fervent folk religion. We know of the paradoxical research that shows that at a time when church attendance's are still in decline the proportion of people who believe in a 
divine being, the power of prayer and in a spiritual dimension to life remains very high. Our own profession has not been particularly good at recognising that, since this must be definition by regarded as part of normal psychology, we must pay some attention to it if we claim to practise holistically.

It so happened that around this time I was studying the ancient myths of the Goddess. I had been reading about the archaeological finds in this century which changed the view of religious history. From the dawn of time through thousands of years the Great Mother was worshipped until the conquest of her settled agrarian people by nomadic tribes worshipping warrior gods led to her subordination and then her almost complete suppression by the patriarchal religions of Judaism. Christianity and Islam. She has never been totally lost, the Shekinah and Sophia (feminine principles of God's presence and wisdom), the church as bride of Christ, the cult of the Virgin Mary have taken some of her attributes. However, this has been a partial and disfigured form and many theologians argue that these images have done more harm than good to a holistic and synthesised view of the masculine and feminine archetypes, and have been used to enhance patriarchal power and ensure the religious subjugation of women. In these circumstances, the feminine is likely to persist in individual symbols and come through in folk religion. Flowers, the sexual organs of plants, and lights have always been sacred to the Goddess and are used in a quiet non-rebellious way in ceremonial and in the spontaneous shrines to Diana.

Much of the expressed grief referred back to the golden time of her wedding to Prince Charles. Every wedding carries huge emotional, familial, sexual, dynastic, societal, spiritual, financial and political implications. The rite of passage in which Kore, the maiden, the pre-sexual, vulnerable girl child becomes the Mother, sexually active and fertile by union with the male in his own transition is an archetypal situation. Although the death of young mothers has sadly been a tragic reality down the millennia it has never had an archetypal justification; it is always felt as an outrage against nature. Deprived suddenly of our own national image of the girlwoman who combined Maiden and Mother (as Marilyn Monroe combined Maiden and Whore) is it surprising that many people felt personally bereaved and dislocated? Is it surprising that there was suddenly an almost desperate need for the third person of the Goddess trinity, the
Crone, wise woman or Hag (now a term of disgust but originally meaning (most holy one') that our national religion was quite unable to meet? All those people outside Buckingham Palace criticising the Queen, calling on her to return to London - is it fanciful to hear in them the petulant and longing cry of worshippers throughout the ages, "come back to us great mother, your children are afraid'? I doubt if I was the only person to feel a totally illogical sense of relief when the Queen came back and addressed her people. Was she just an elderly lady, coping with what dignity she could muster, in a rather squalid family tragedy, or was she for a time invested with the mother Goddess who returns the world to order by receiving back the dead in readiness for rebirth?

In reflecting on these things I am doing more than playing with symbols. The practice of psychiatry has wonderful potential to be a true synthesis of the masculine power of science and the feminine art of healing, but only if the shell of psychiatric ideology is filled with the fruit of human experience, offered with heart. The events surrounding Diana's death have thrown up further antagonisms, such as that between the 'stiff upper lip brigade' (thought) and the 'touchy-feely lot' (emotion). Those who prefer expressed emotion and those who find solace in reticence and dignity seem to find it difficult to tolerate each other, but society needs to hold both in creative tension to benefit the whole. In the same way I am not suggesting we should return to the worship of the Mother Goddess or overthrow the whole Judaeo-Christian tradition. Over many years in my inner life I have been trying to bring into harmony the opposites within myself, feeling and thought, receptivity and activity, spirit and matter, vulnerability and strength, feminine and masculine, and this became caught up in the public drama in a way which was productive for me on many levels. Maybe it was for you too

We all live by myths, whether we are conscious of them or not and part of our work is to help others to make sense of their lives, and give them permission to recognise their own myths. Our national myths need to be renewed constantly by finding new shapes for ancient archetypes. Above all we need a new synthesis not just privately but publicly. We need a new sacred marriage between the Goddess and the God.

Elinor Kapp, Retired Consultant Psychiatrist, 46 Cathedral Road, Cardiff CF1 9LL 